\title{
Fruit and vegetable consumption - the influence of aspects associated with trust in food and safety and quality of food
}

\author{
Anne W Taylor ${ }^{1, *}$, John Coveney ${ }^{2}$, Paul R Ward ${ }^{2}$, Julie Henderson ${ }^{2}$ \\ Samantha B Meyer ${ }^{2}$, Rhiannon Pilkington ${ }^{1}$ and Tiffany K Gill' \\ 'Population Research \& Outcome Studies, Discipline of Medicine, University of Adelaide, Level 3, 122 Frome \\ Street, Adelaide, SA 5000, Australia: ${ }^{2}$ Public Health, School of Medicine, Flinders University, Adelaide, \\ Australia
}

Submitted 9 December 2010: Accepted 6 June 2011: First published online 2 August 2011

\begin{abstract}
Objective: To profile adults who eat less than the recommended servings of fruit and vegetables per day.

Design: Australia-wide population telephone survey on a random sample of the Australian population, with results analysed by univariate and multivariate models. Setting: Australia.

Subjects: One thousand one hundred and eight interviews, respondents' (49.3\% males) mean age was $45 \cdot 12(\mathrm{sD} 17 \cdot 63)$ years.

Results: Overall $54 \cdot 8 \%$ and $10 \cdot 7 \%$ were eating the recommended number of servings of fruit and vegetables. Variables included in the multivariate model indicating low fruit consumption included gender, age, employment, education and those who were less likely to consider the safety and quality of food as important. In regard to low vegetable consumption, people who were more likely to do the food shopping only 'some of the time' and have a high level of trust in groups of people such as immediate family, neighbours, doctors and different levels of government were included in the final model. They were also less likely to neither consider the safety and quality of food as important nor trust organisations/institutions such as the press, television and politicians. In the final model depicting both low fruit and low vegetable servings, sex, age and a low level of importance with regard to safety and quality of food were included.

Conclusion: To increase fruit and vegetable consumption, research into a broad range of determinants associated with behaviours should be coupled with a deeper understanding of the process associated with changing behaviours. While levels of trust are related to behaviour change, knowledge and attitudes about aspects associated with safety and quality of food are also of importance.
\end{abstract}

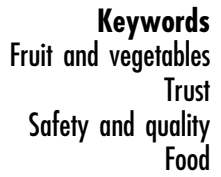

The consumption of fruit and vegetables in Australia and elsewhere is increasingly promoted as healthful ${ }^{(1-4)}$. Fruit and vegetables are seen as good sources of vitamins, minerals and fibre and a valuable component of a balanced, nutritious $\operatorname{diet}^{(3)}$. Promotions and campaigns aimed at increasing the consumption of fruit and vegetables are seen as important steps in counteracting the chronic disease epidemic, with poor nutrition a major risk factor for conditions such as diabetes, cancer and heart disease ${ }^{(5)}$. With the alarming rise in the obesity prevalence rates, increased emphasis has also been placed upon healthy weight and the relationship between fruit and vegetable intake and $\mathrm{BMI}^{(3)}$.

Behaviours associated with good nutrition are related to levels of consumer trust ${ }^{(6,7)}$. Many theoretical models posit that the prerequisites required for behaviour change include an acknowledgement by the individual of the problem, issue or risk ${ }^{(8,9)}$. That is to say, to believe in, or act upon, health promotion messages individuals need to be aware of either levels of risk or levels of trust related to the desired behaviour change ${ }^{(10-12)}$. One of the main levels of trust in terms of trust in food is in the overall safety and quality of the food supplied ${ }^{(13,14)}$. This covers consumer trust in producers, the suppliers, the packaging and the content. Another prerequisite for trust is that the health promotion message/campaign is correct and from reputable organisations ${ }^{(15)}$. A level of trust in the credibility of the message and in the organisation promoting the message is required before individuals contemplate changing their behaviour appropriately ${ }^{(12,16,17)}$; as Hansen et $a l^{(18)}$ suggested, if people do not 'trust the messenger, they will not trust the message' (p. 15). Studies from Europe suggest that trust in the media, farmers, politicians and the food industry has diminished in the face 
of well-publicised food scares, with consumers more likely to trust information about healthy eating received from medical practitioners and consumer groups than information received through the media ${ }^{(19,20)}$. Adolescents, in contrast, are more likely to trust information about healthy eating received from family members, teachers or the medical profession, but also place little credence in information received through the media ${ }^{(21)}$. One Australian study has also identified diminishing trust in the motives of organisations such as the Heart Foundation ${ }^{(7)}$. Therefore knowing more about consumer trust in the food system, and in expert advice, can provide better ways to improve and tailor communication about health and food ${ }^{(22,23)}$.

The broad aim of the present study was to examine the relationship between consumption of fruits and vegetables and consumer trust related to a number of aspects of the food supply in order to better understand the characteristics of groups in the population who are not eating sufficient amounts of fruit and vegetables.

\section{Methods}

The Food and Trust study, a collaboration between Flinders University of South Australia and the South Australian Health Department, was funded by the Australian Research Council (ARC) under the ARC Discovery scheme. In the study a survey of randomly selected Australian adults was undertaken to identify the nature and level of consumer trust in the Australian food supply. Factors that influence food trust in different socio-economic groups in the Australian population were examined in the survey, as were key theoretical claims about the relationship between food and trust. The hypothesis tested with the research was that trust in the messages being produced will not be present if, first, there is no trust in society in a broad sense and, second, no sense that regulatory values such as food safety requirements and the monitoring of food standards are important endeavours. Previous publications have highlighted qualitative findings from these early components of the study ${ }^{(24-27)}$. Moreover the study also provided a unique opportunity to assess fruit and vegetable consumption against a broad range of variables associated with trust. The present paper reports on this component of the analysis, looking particularly at these aspects in regard to fruit and vegetable consumption.

Participants in the survey were randomly selected from the Australian Electronic White Pages (EWP) and a simple random sample was employed. All households in Australia with a telephone connected and the telephone number listed in the Australian EWP were eligible for selection in the sample. An approach letter, on Flinders University of South Australia letterhead, was sent to all selected households detailing the purpose of the study and notifying the households they would receive a telephone call. Along with the letter there was also an information sheet containing the purpose and benefits of the research, the format of the survey, and how more detail could be obtained. Within each contacted household a random person (the person, aged 18 years or over, who was last to have a birthday) was selected. Prior to the main survey, a pilot study of fifty-two randomly selected households was conducted to test question formats and question sequence, and to assess survey procedures. The questionnaire was amended on the basis of the information obtained.

Data collection was undertaken by the contracted agency from October to December 2009 and professional interviewers conducted the interviews. Interviews were conducted using computer-assisted telephone interview methodology which allows immediate entry of data from the interviewer's questionnaire screen to the computer database. There was no replacement for non-contactable persons. A minimum of ten call-backs were made to telephone numbers selected to interview household members and different times of the day or evening were scheduled for each call-back. If the person could not be interviewed immediately they were re-scheduled for interview at a time suitable to them. Replacement interviews for persons who could not be contacted or interviewed were not permitted. Ten per cent of each interviewer's work was randomly selected for validation by the supervisor. On average, interviews took $14.5 \mathrm{~min}$ to complete.

The overall sample response rate was $41 \cdot 2 \%$. Initially a sample of 4100 was drawn. Sample loss of 1408 occurred due to non-connected numbers ( $n$ 1060), non-residential numbers ( $n$ 135), ineligible households ( $n$ 139) and fax/ modem connections ( $n$ 74). The data were weighted by age and sex to reflect the structure of the Australian population 18 years and over using the Australian Bureau of Statistics 2007 Estimated Residential Population. Weighting was used to correct for areas of disproportion within the sample with respect to the population of interest. The weights reflect unequal sample inclusion probabilities and compensate for differential non-response.

Demographic questions asked included age, sex, household size, marital status, work status, country of birth, highest education level obtained, housing status and annual household income. The two questions relating to fruit and vegetable consumption were the standard questions used in Australia ('How many serves of vegetables/fruit do you usually eat each day?'). Respondents were deemed to not be eating the recommended number if they reported less than five servings of vegetables or two servings of fruits daily. Other relevant questions included in the analysis assessed how often food prices were considered before health and nutritional qualities and how much of the household shopping was undertaken by the respondent.

Eight questions were asked about safety and quality concerns when purchasing food and recoded into an 'overall level of importance of safety and quality' variable. 
These included the importance of knowing staff personally, of knowing if the food is labelled with full product information, that the food producer or shop/retailer maintains control of hygiene, of knowing where the food originates, and of knowing that local hygiene inspectors visit the premises regularly. The response categories of 'unimportant', 'matters a bit' and 'don't know' were coded as 0 while 'important' responses were coded as 1 . The total responses were summed (range 0 to 8 ) and entered into analyses as a continuous variable.

The second recoded variable related to the importance of who monitors the safety and quality of food' and included six questions about food scientists, consumer organisations such as the Heart Foundation/Choice, press, radio and television, and different levels of government (local, state, federal) and were scaled into an importance of monitoring organisations' variable. 'Very important' responses were coded as 1, while 'quite important', 'not important' or 'don't know' categories were coded as 0 . The total responses were summed (range 0 to 6) and entered into analyses as a continuous variable.

The third scaled score related to overall trust in groups with twelve individual questions asking about the 'overall trust in groups' such as immediate family, neighbours, regular doctor, doctors in general, hospitals (private and public), legal system, banks and different levels of government. 'Trust them completely' were coded as 1 , while 'trust them most of the time', 'do not trust them very much', 'do not trust them at all' and 'don't know' were coded as 0 . The total responses were summed (range 0 to 12) and entered into analyses as a continuous variable.

The fourth scaled score was a 'level of trust of organisations following a food scandal' concerning chicken production in Australia and included four questions on trust of supermarket chains, farmers, politicians and press, television and radio. 'Complete trust' and 'have some trust' were coded as 1 , while 'have some distrust', 'completely distrust' and 'don't know' were coded as 0. The total responses were summed (range 0 to 12) and entered into analyses as a continuous variable.

Respondents were also asked four questions about how much they 'trusted people/organisations' and covered press, television and radio, politicians, supermarket chains, farmers and politicians in general. 'Complete trust' was coded as 1, while 'some trust', 'some distrust', 'complete distrust' and 'don't know' were coded as 0 . The total responses were summed (range 0 to 4) and entered into analyses as a continuous variable.

Three analyses were undertaken. First, associations between those not eating the recommended number of fruit servings per day, compared with those eating the recommended number of servings, and the sociodemographic, trust-related and other variables were determined using univariate analyses. Here, $\chi^{2}$ tests were undertaken to compare differences. A multivariate logistic regression model was subsequently developed, including all variables with a $P$ value $<0 \cdot 25$ at the univariate level ${ }^{(28)}$, in order to ascertain independently associated factors. The second set of analyses followed the same procedure but assessed vegetable servings with the range of sociodemographic and trust-related variables. The third analysis compared those eating less than the recommended number of fruit and vegetable (combined) servings against those eating the recommended number of servings using the same procedure.

Data were analysed using the statistical software packages SPSS for Windows version $17 \cdot 0$ (SPSS Inc., Chicago, IL, USA) and STATA version 10 (StataCorp., College Station, TX, USA). The research was carried out according to the Ethical Guidelines for Social and Behavioural Research B (January 2008) produced by the Social and Behavioural Research Ethics Committee of Flinders University of South Australia.

\section{Results}

Overall $49 \cdot 3 \%$ of the sample was male and the mean age was $45 \cdot 12$ (SD $17 \cdot 63)$ years. Overall $54 \cdot 8 \%$ (95\% CI $51 \cdot 2$, $58 \cdot 3)$ were eating the recommended number of fruit servings and $10.7 \%(95 \%$ CI $8 \cdot 8,12.9)$ were eating the recommended number of vegetable servings each day. In total, $7 \cdot 7 \%(95 \% \mathrm{CI} 6 \cdot 3,9 \cdot 5)$ were eating the recommended daily servings of both fruit and vegetables.

Tables 1 and 2 detail the univariate relationship between inadequate fruit consumption and the range of demographic variables, related food variables and the scaled trust variables, with significant differences highlighted. Table 3 details the final multivariate model (Hosmer-Lemeshow $\chi^{2}=9 \cdot 77, \quad P=0.2815$ ) with four demographic and one food-related variables included in the final model that best jointly predicts a person who has inadequate fruit consumption. Tables 4 and 5 highlight the univariate analysis assessing the range of variables against inadequate vegetable consumption. Table 6 details the multivariate model (Hosmer-Lemeshow $\chi^{2}=13 \cdot 50$, $P=0 \cdot 0959$ ) with no demographic variables but four foodand/or trust-related variables included in the final model that best jointly predicts a person who has inadequate vegetable consumption. In the final model comparing combined inadequate fruit and vegetable consumption, two demographic and one food-related question proved significant in the final model (Tables 7-9; Hosmer-Lemeshow $\left.\chi^{2}=14 \cdot 63, P=0 \cdot 0667\right)$.

\section{Discussion}

The present results show that broad levels of trust in the community, and in the importance of monitoring food standards, have, in varying degrees, relationships with the consumption of the recommended servings of either fruit or vegetables. Our multivariate modelling indicated that 
Table 1 Univariate analysis of demographic variables associated with eating less than the recommended servings of fruit per day among a random sample of the adult Australian population, 2009

\begin{tabular}{|c|c|c|c|c|c|}
\hline & $n / N$ & $\%$ & OR & $95 \%$ OR & $P$ value \\
\hline \multicolumn{6}{|l|}{ Sex } \\
\hline Female & $217 / 562$ & $38 \cdot 5$ & $1 \cdot 00$ & & \\
\hline Male & $285 / 547$ & $52 \cdot 1$ & $1 \cdot 74$ & $1 \cdot 30,2 \cdot 32$ & $<0.001$ \\
\hline \multicolumn{6}{|l|}{ Age (years) } \\
\hline $75+$ & $32 / 87$ & $36 \cdot 6$ & $1 \cdot 00$ & & \\
\hline $55-74$ & 96/252 & $38 \cdot 0$ & $1 \cdot 06$ & $0 \cdot 64,1 \cdot 76$ & $0 \cdot 814$ \\
\hline $35-54$ & $205 / 399$ & $51 \cdot 3$ & $1 \cdot 83$ & $1 \cdot 10,3.03$ & 0.020 \\
\hline $18-34$ & $169 / 370$ & $45 \cdot 6$ & $1 \cdot 45$ & $0 \cdot 82,2 \cdot 58$ & $0 \cdot 201$ \\
\hline \multicolumn{6}{|l|}{ Household size } \\
\hline One & $76 / 177$ & $42 \cdot 7$ & $1 \cdot 00$ & & \\
\hline Two & $153 / 345$ & $44 \cdot 3$ & $1 \cdot 06$ & $0.72,1.58$ & $0 \cdot 753$ \\
\hline Three or more & $273 / 586$ & $46 \cdot 6$ & $1 \cdot 17$ & $0 \cdot 80,1 \cdot 71$ & 0.419 \\
\hline \multicolumn{6}{|l|}{ Marital status* } \\
\hline Married/living with partner & $300 / 664$ & $45 \cdot 1$ & $1 \cdot 00$ & & \\
\hline Separated/divorced & $42 / 91$ & $45 \cdot 9$ & $1 \cdot 03$ & $0.68,1.57$ & 0.885 \\
\hline Widowed & $20 / 58$ & $35 \cdot 0$ & 0.66 & $0 \cdot 38,1 \cdot 12$ & $0 \cdot 123$ \\
\hline Never married & $138 / 293$ & $47 \cdot 0$ & $1 \cdot 08$ & $0.73,1.59$ & 0.698 \\
\hline \multicolumn{6}{|l|}{ Work status* } \\
\hline $\begin{array}{l}\text { Unemployed/economically inactive } \\
\text { (home duties, student, unable to work, other) }\end{array}$ & $73 / 196$ & $37 \cdot 3$ & $1 \cdot 00$ & & \\
\hline Full-time employed & $256 / 507$ & $50 \cdot 6$ & $1 \cdot 72$ & $1 \cdot 10,2 \cdot 68$ & 0.016 \\
\hline Part-time employed & $94 / 204$ & $46 \cdot 1$ & $1 \cdot 44$ & $0.88,2 \cdot 35$ & $0 \cdot 146$ \\
\hline Retired & $77 / 199$ & $38 \cdot 6$ & 1.06 & $0.67,1.67$ & 0.815 \\
\hline \multicolumn{6}{|l|}{ Country of birth* } \\
\hline Other & $86 / 218$ & $39 \cdot 4$ & $1 \cdot 00$ & & \\
\hline Australia & $415 / 887$ & $46 \cdot 8$ & $1 \cdot 36$ & $0.94,1.94$ & 0.097 \\
\hline \multicolumn{6}{|l|}{ Education } \\
\hline Degree or higher & $109 / 274$ & $39 \cdot 7$ & $1 \cdot 00$ & & \\
\hline Trade, certificate, diploma & $165 / 345$ & $47 \cdot 6$ & $1 \cdot 38$ & $0.94,2.04$ & $0 \cdot 104$ \\
\hline No schooling to secondary & $228 / 489$ & $46 \cdot 6$ & $1 \cdot 33$ & $0.91,1.94$ & $0 \cdot 144$ \\
\hline \multicolumn{6}{|l|}{ Dwelling } \\
\hline Owned or being purchased & $399 / 897$ & $44 \cdot 5$ & $1 \cdot 00$ & & \\
\hline Rented housing trust/privately & 92/189 & $48 \cdot 5$ & $1 \cdot 17$ & $0 \cdot 76,1 \cdot 81$ & $0 \cdot 466$ \\
\hline Retirement/other/refused & $11 / 22$ & $49 \cdot 0$ & $1 \cdot 20$ & $0.43,3.33$ & 0.727 \\
\hline \multicolumn{6}{|l|}{ Annual income (\$AU) } \\
\hline Up to 20000 & $54 / 121$ & $45 \cdot 0$ & $1 \cdot 00$ & & \\
\hline $20001-60000$ & $141 / 322$ & $43 \cdot 9$ & 0.95 & $0.61,1.50$ & 0.834 \\
\hline $60001-100000$ & $113 / 253$ & $44 \cdot 5$ & 0.98 & $0.61,1.57$ & 0.924 \\
\hline $100001+$ & $115 / 243$ & $47 \cdot 3$ & $1 \cdot 10$ & $0.70,1.79$ & $0 \cdot 715$ \\
\hline Not stated/refused/don't know & $78 / 170$ & $46 \cdot 1$ & 1.04 & $0 \cdot 60,1 \cdot 81$ & 0.884 \\
\hline
\end{tabular}

*Not stated category not reported.

Table 2 Univariate analysis of related food variables and scaled trust variables associated with eating less than the recommended servings of fruit per day among a random sample of the adult Australian population, 2009

\begin{tabular}{|c|c|c|c|c|c|}
\hline & $n / N$ & $\%$ & OR & $95 \%$ OR & $P$ value \\
\hline \multicolumn{6}{|l|}{ Consider food prices before health and nutrition } \\
\hline Often/sometimes & $273 / 573$ & $47 \cdot 7$ & $1 \cdot 00$ & & \\
\hline Seldom/never & $221 / 522$ & $42 \cdot 5$ & $0 \cdot 81$ & $0.61,1.08$ & $0 \cdot 153$ \\
\hline Don't know/refused & $7 / 14$ & $48 \cdot 6$ & 1.04 & $0.36,2.99$ & 0.945 \\
\hline \multicolumn{6}{|l|}{ How much of the food shopping do you do? } \\
\hline A lot & $303 / 705$ & $43 \cdot 0$ & $1 \cdot 00$ & & \\
\hline Some & $124 / 247$ & $50 \cdot 2$ & 1.34 & $0.92,1.95$ & $0 \cdot 120$ \\
\hline None/very little & $75 / 157$ & $47 \cdot \overline{5}$ & $1 \cdot 20$ & $0.75,1.92$ & 0.442 \\
\hline Overall level of importance with regard to the safety and quality of food & - & - & $0 \cdot 87$ & $0.81,0.93$ & $<0.001$ \\
\hline Importance of organisations monitoring safety and quality & - & - & 1.04 & $1.00,1.09$ & 0.059 \\
\hline Overall trust in groups & _ & _ & $1 \cdot 01$ & $0.99,1.03$ & 0.539 \\
\hline Overall trust in people/institutions & - & - & $1 \cdot 04$ & $0.97,1 \cdot 12$ & 0.253 \\
\hline Trust in groups following food scandal & - & - & 1.00 & $0.90,1.12$ & 0.944 \\
\hline
\end{tabular}

persons who did not eat the recommended number of servings of fruit per day were more likely to be male, aged 35 to 44 years, employed full time or retired, have a low level of education and be less likely to consider the safety and quality of food as important. In terms of vegetable consumption, people who ate less than the recommended number of servings per day were more likely to do the food shopping only 'some of the time' and 
Table 3 Multivariate analysis of variables associated with respondents consuming less than the recommended servings of fruit per day among a random sample of the adult Australian population, 2009

\begin{tabular}{|c|c|c|c|}
\hline & OR & $95 \%$ OR & $P$ value \\
\hline \multicolumn{4}{|l|}{ Sex } \\
\hline Female & $1 \cdot 00$ & & \\
\hline Male & 1.55 & $1 \cdot 13,2 \cdot 11$ & 0.006 \\
\hline \multicolumn{4}{|l|}{ Age (years) } \\
\hline $75+$ & $1 \cdot 00$ & & \\
\hline $55-74$ & $1 \cdot 12$ & $0.65,1.92$ & 0.692 \\
\hline $35-54$ & 1.90 & $1.01,3.56$ & 0.045 \\
\hline 18-34 & $1 \cdot 42$ & $0 \cdot 70,2 \cdot 86$ & 0.332 \\
\hline \multicolumn{4}{|l|}{ Work status* } \\
\hline $\begin{array}{l}\text { Unemployed/economically inactive } \\
\text { (home duties, student, unable to work, other) }\end{array}$ & $1 \cdot 00$ & & \\
\hline Full-time employed & $1 \cdot 82$ & $1 \cdot 10,2 \cdot 98$ & 0.036 \\
\hline Part-time employed & 1.67 & $0.96,2 \cdot 89$ & 0.069 \\
\hline Retired & $1 \cdot 85$ & $1 \cdot 05,3 \cdot 24$ & 0.032 \\
\hline \multicolumn{4}{|l|}{ Education } \\
\hline Degree or higher & $1 \cdot 00$ & & \\
\hline Trade, certificate, diploma & 1.53 & $1 \cdot 03,2 \cdot 28$ & 0.037 \\
\hline No schooling to secondary & $1 \cdot 70$ & $1 \cdot 14,2 \cdot 52$ & 0.009 \\
\hline Overall level of importance with regard to the safety and quality of food & 0.87 & $0.81,0.94$ & $<0.001$ \\
\hline
\end{tabular}

${ }^{\star}$ Not stated category not reported.

Table 4 Univariate analysis of demographic variables associated with eating less than the recommended servings of vegetables per day among a random sample of the adult Australian population, 2009

\begin{tabular}{|c|c|c|c|c|c|}
\hline & $n / N$ & $\%$ & OR & $95 \%$ OR & $P$ value \\
\hline \multicolumn{6}{|l|}{ Sex } \\
\hline Female & $490 / 562$ & $87 \cdot 3$ & $1 \cdot 00$ & & \\
\hline Male & $499 / 546$ & $91 \cdot 4$ & 1.54 & $0.96,2 \cdot 48$ & 0.074 \\
\hline \multicolumn{6}{|l|}{ Age (years) } \\
\hline $75+$ & $74 / 87$ & $84 \cdot 8$ & 1.00 & & \\
\hline $55-74$ & $213 / 251$ & $84 \cdot 8$ & $1 \cdot 00$ & $0.51,1.94$ & 0.994 \\
\hline $35-54$ & $360 / 399$ & $90 \cdot 4$ & 1.69 & $0.84,3.93$ & 0.139 \\
\hline $18-34$ & $342 / 370$ & $92 \cdot 3$ & $2 \cdot 15$ & $0 \cdot 88,5 \cdot 21$ & 0.091 \\
\hline \multicolumn{6}{|l|}{ Household size } \\
\hline One & $155 / 176$ & $88 \cdot 2$ & $1 \cdot 00$ & & \\
\hline Two & $297 / 346$ & $86 \cdot 0$ & $0 \cdot 83$ & $0.48,1.42$ & 0.491 \\
\hline Three or more & $536 / 586$ & $91 \cdot 6$ & 1.46 & $0 \cdot 81,2 \cdot 66$ & $0 \cdot 210$ \\
\hline \multicolumn{6}{|l|}{ Marital status ${ }^{*}$} \\
\hline Married/living with partner & $590 / 665$ & $88 \cdot 7$ & 1.00 & & \\
\hline Separated/divorced & $78 / 90$ & $86 \cdot 7$ & 0.83 & $0.44,1.56$ & 0.561 \\
\hline Widowed & $48 / 58$ & $82 \cdot 3$ & 0.59 & $0.27,1.30$ & $0 \cdot 190$ \\
\hline Never married & $271 / 292$ & $92 \cdot 8$ & 1.63 & $0.79,3.37$ & $0 \cdot 188$ \\
\hline \multicolumn{6}{|l|}{ Work status* ${ }^{*}$} \\
\hline Retired & $170 / 200$ & $84 \cdot 9$ & 1.00 & & \\
\hline Part-time employed & $177 / 204$ & $86 \cdot 9$ & $1 \cdot 18$ & $0.71,1.97$ & $0 \cdot 141$ \\
\hline Full-time employed & $458 / 507$ & $90 \cdot 3$ & $1 \cdot 65$ & $0.99,2 \cdot 77$ & 0.057 \\
\hline $\begin{array}{l}\text { Unemployed/economically inactive } \\
\text { (home duties, student, unable to work, other) }\end{array}$ & $183 / 195$ & $93 \cdot 8$ & $2 \cdot 69$ & $1 \cdot 28,5 \cdot 65$ & 0.009 \\
\hline \multicolumn{6}{|l|}{ Country of birth ${ }^{*}$} \\
\hline Australia & $788 / 886$ & $89 \cdot 0$ & $1 \cdot 00$ & & \\
\hline Other & $198 / 219$ & $90 \cdot 4$ & $1 \cdot 17$ & $0 \cdot 63,2 \cdot 15$ & 0.611 \\
\hline \multicolumn{6}{|l|}{ Education } \\
\hline Degree or higher & $246 / 274$ & $89 \cdot 8$ & $1 \cdot 00$ & & \\
\hline Trade, certificate, diploma & $300 / 345$ & $87 \cdot 1$ & $0 \cdot 77$ & $0 \cdot 42,1 \cdot 40$ & 0.392 \\
\hline No schooling to secondary & $443 / 489$ & $90 \cdot 6$ & $1 \cdot 10$ & $0.61,1.98$ & 0.741 \\
\hline \multicolumn{6}{|l|}{ Dwelling $^{*}$} \\
\hline Owned or being purchased & $797 / 896$ & $89 \cdot 0$ & $1 \cdot 00$ & & \\
\hline Rented housing trust/privately & $170 / 189$ & $90 \cdot 1$ & $1 \cdot 13$ & $0.54,2 \cdot 37$ & 0.752 \\
\hline \multicolumn{6}{|l|}{ Annual income (\$AU) } \\
\hline $100001+$ & $214 / 243$ & $88 \cdot 0$ & 1.00 & & \\
\hline $60001-100000$ & $235 / 253$ & $92 \cdot 7$ & $1 \cdot 74$ & $0.84,3.66$ & $0 \cdot 138$ \\
\hline $20001-60000$ & $279 / 321$ & $86 \cdot 9$ & 0.91 & $0.49,1.67$ & 0.759 \\
\hline Up to 20000 & $108 / 120$ & $90 \cdot 1$ & $1 \cdot 25$ & $0.60,2.59$ & 0.556 \\
\hline Not stated/refused/don't know & $153 / 170$ & $90 \cdot 1$ & $1 \cdot 24$ & $0.61,2 \cdot 55$ & 0.552 \\
\hline
\end{tabular}

${ }^{*}$ Not stated category not reported. 
Table 5 Univariate analysis of related food variables and scaled trust variables associated with eating less than the recommended servings of vegetables per day among a random sample of the adult Australian population, 2009

\begin{tabular}{|c|c|c|c|c|c|}
\hline & $n / N$ & $\%$ & OR & $95 \%$ OR & $P$ value \\
\hline \multicolumn{6}{|l|}{ Consider food prices before health and nutrition* } \\
\hline Seldom/never & $458 / 521$ & $87 \cdot 9$ & $1 \cdot 00$ & & \\
\hline Often/sometimes & $517 / 572$ & $90 \cdot 3$ & $1 \cdot 29$ & $0.83,1.99$ & 0.256 \\
\hline \multicolumn{6}{|l|}{ How much of the food shopping do you do? } \\
\hline A lot & $615 / 705$ & $87 \cdot 2$ & & & \\
\hline Some & $232 / 247$ & $93 \cdot \overline{9}$ & $2 \cdot 25$ & $1 \cdot 22,4 \cdot 14$ & 0.010 \\
\hline None/very little & $143 / 156$ & $91 \cdot 6$ & $1 \cdot 59$ & $0.64,3.92$ & $0 \cdot 314$ \\
\hline Overall level of importance with regard to the safety and quality of food & - & - & 0.86 & $0.77,0.96$ & 0.005 \\
\hline Overall importance of organisations monitoring safety and quality & - & - & $1 \cdot 04$ & $0 \cdot 99,1 \cdot 10$ & $0 \cdot 132$ \\
\hline Overall trust in groups & - & - & $1 \cdot 03$ & $1.00,1.06$ & 0.034 \\
\hline Overall trust in people/institutions & _ & - & 0.93 & $0.85,1.02$ & $0 \cdot 135$ \\
\hline Trust in groups following food scandal & - & - & 1.03 & $0 \cdot 88,1 \cdot 20$ & $0 \cdot 743$ \\
\hline
\end{tabular}

${ }^{*}$ Not stated category not reported.

Table 6 Multivariate analysis of variables associated with respondents consuming less than the recommended servings of vegetables per day among a random sample of the adult Australian population, 2009

\begin{tabular}{llll}
\hline & OR & $95 \%$ OR & $P$ value \\
\hline How much of the food shopping do you do? & & & \\
A lot & $1 \cdot 00$ & & \\
Some & $2 \cdot 21$ & $1 \cdot 17,4 \cdot 18$ & 0.014 \\
None/very little & 1.50 & $0.62,3.62$ & 0.371 \\
Overall level of importance with regard to the safety and quality of food & 0.87 & $0 \cdot 78,0.97$ & 0.014 \\
Overall trust in groups & 1.06 & $1.02,1 \cdot 10$ & 0.003 \\
Overall trust in people/institutions & 0.86 & $0.76,0.96$ & 0.009 \\
\hline
\end{tabular}

have a high level of trust in groups of people such as immediate family, neighbours, doctors, banks and different levels of government. They were also less likely to consider the safety and quality of food as important or to trust organisations/institutions such as the press, radio and television, politicians and farmers. Interestingly, when the multivariate modelling was undertaken on the combined fruit and vegetable consumption, those who did not eat the recommended servings of fruit and vegetables were more likely to be male and aged 18 to 34 years, and they were also less likely to consider the safety and quality of food as important.

The prevalence of fruit and vegetable consumption in the present study was in line with other Australian research ${ }^{(29-31)}$. Australian and international studies have shown lower consumption of both fruit and vegetables for males compared with females ${ }^{(32-34)}$, although other studies have shown, as found in our study, that men eat less fruit but not necessarily less vegetables than women $^{(35,36)}$. In terms of education level, many of the studies assessing socio-economic differences associated with fruit and vegetable consumption have shown that the lower educated consume both less fruit and less vegetables ${ }^{(36-39)}$, although the variable assessing education in our study was significant only in the final fruit consumption model. Somewhat surprisingly, many variables that have been shown to have a relationship with fruit and vegetable consumption did not reach significance in any of our multivariate models. This included household income, where other research has consistently shown that people on lower incomes eat less fruit and vegetables ${ }^{(38-40)}$. The lack of significance in our study could be the result of a smaller number of income categories although another Australian study has also reported a lack of association between fruit and vegetable consumption and household income ${ }^{(29)}$.

The fact that men who work full time are less likely to eat fruit has also been reported, with the subjective interpretation that eating fruit at a morning tea break, for example, especially in more male-dominated professions, is not seen as ' $\mathrm{COOl}^{\text {'(41) }}$. In terms of health promotion campaigns targeted at specific groups, this could be one area worth exploring. The decrease in fruit consumption of older retired males has also been previously reported ${ }^{(39,42)}$ and again could be a group worthy of specific targeting. Retirement has been shown to result in weight gain, especially in those who had active jobs formerly ${ }^{(43)}$.

The overriding finding of the present analyses was the significance of the variable assessing the level of importance of safety and quality issues, with the odds ratio of this variable significantly decreased in all three models. This means that when buying food, assessing the importance of producers or the shop/retailer, the control of hygiene, knowing the staff personally, knowing the origin of the food, the regularity of local hygiene inspectors, Australian authorities enforcing strict hygienic standards, knowing the shop from previous experience and the food being labelled with full product information 
Table 7 Univariate analysis of demographic variables associated with eating less than the recommended servings of fruit and vegetables per day among a random sample of the adult Australian population, 2009

\begin{tabular}{|c|c|c|c|c|c|}
\hline & $n / N$ & $\%$ & OR & $95 \%$ OR & $P$ value \\
\hline \multicolumn{6}{|l|}{ Sex } \\
\hline Female & $502 / 561$ & $89 \cdot 4$ & $1 \cdot 00$ & & \\
\hline Male & $520 / 546$ & $95 \cdot 3$ & $2 \cdot 39$ & $1 \cdot 40,4 \cdot 07$ & 0.001 \\
\hline \multicolumn{6}{|l|}{ Age (years) } \\
\hline $75+$ & $75 / 87$ & $86 \cdot 0$ & $1 \cdot 00$ & & \\
\hline $55-74$ & $220 / 251$ & $87 \cdot 7$ & $1 \cdot 16$ & $0 \cdot 58,2 \cdot 32$ & 0.679 \\
\hline $35-54$ & $369 / 399$ & $92 \cdot 6$ & $2 \cdot 05$ & $0 \cdot 98,4 \cdot 27$ & 0.055 \\
\hline $18-34$ & $357 / 370$ & $96 \cdot 5$ & 4.53 & $1 \cdot 59,12 \cdot 88$ & 0.005 \\
\hline \multicolumn{6}{|l|}{ Household size } \\
\hline One & $159 / 176$ & $90 \cdot 4$ & $1 \cdot 00$ & & \\
\hline Two & $305 / 345$ & $88 \cdot 4$ & $0 \cdot 80$ & $0.44,1.46$ & 0.469 \\
\hline Three or more & $557 / 586$ & $95 \cdot 2$ & $2 \cdot 07$ & $1 \cdot 07,4 \cdot 00$ & 0.030 \\
\hline \multicolumn{6}{|l|}{ Marital status* } \\
\hline Married/living with partner & $609 / 664$ & $91 \cdot 6$ & $1 \cdot 00$ & & \\
\hline Separated/divorced & $80 / 91$ & $88 \cdot 5$ & $0 \cdot 70$ & $0.36,1 \cdot 38$ & 0.302 \\
\hline Widowed & $48 / 58$ & $83 \cdot 1$ & 0.45 & $0.20,1.02$ & 0.055 \\
\hline Never married & $282 / 292$ & $96 \cdot 7$ & $2 \cdot 70$ & $1 \cdot 08,6 \cdot 73$ & 0.033 \\
\hline \multicolumn{6}{|l|}{ Work status* } \\
\hline Retired & $173 / 199$ & $86 \cdot 9$ & $1 \cdot 00$ & & \\
\hline Part-time employed & $184 / 204$ & $90 \cdot 4$ & $1 \cdot 42$ & $0 \cdot 83,2 \cdot 43$ & $0 \cdot 198$ \\
\hline Full-time employed & $478 / 507$ & $94 \cdot 4$ & $2 \cdot 53$ & $1 \cdot 44,4 \cdot 43$ & 0.001 \\
\hline $\begin{array}{l}\text { Unemployed/economically inactive } \\
\text { (home duties, student, unable to work, other) }\end{array}$ & $185 / 195$ & $94 \cdot 4$ & $2 \cdot 55$ & $1 \cdot 15,5 \cdot 65$ & 0.021 \\
\hline \multicolumn{6}{|l|}{ Country of birth* } \\
\hline Australia & $813 / 886$ & $91 \cdot 8$ & $1 \cdot 00$ & & \\
\hline Other & $205 / 218$ & $94 \cdot 2$ & 1.44 & $0 \cdot 73,2 \cdot 83$ & 0.289 \\
\hline \multicolumn{6}{|l|}{ Education } \\
\hline No schooling to secondary & $452 / 488$ & $92 \cdot 4$ & $1 \cdot 00$ & & \\
\hline Trade, certificate, diploma & $315 / 345$ & $91 \cdot 3$ & $0 \cdot 86$ & $0.52,1.43$ & 0.559 \\
\hline Degree or higher & $256 / 274$ & $93 \cdot 2$ & $1 \cdot 13$ & $0.63,2.00$ & 0.688 \\
\hline \multicolumn{6}{|l|}{ Dwelling } \\
\hline Owned or being purchased & $819 / 896$ & $91 \cdot 4$ & $1 \cdot 00$ & & \\
\hline Rented housing trust/privately & $181 / 189$ & $95 \cdot 9$ & $2 \cdot 21$ & $0 \cdot 84,5 \cdot 78$ & $0 \cdot 107$ \\
\hline Retirement/other/refused & $21 / 22$ & $96 \cdot 8$ & $2 \cdot 86$ & $0.37,22 \cdot 08$ & 0.312 \\
\hline \multicolumn{6}{|l|}{ Annual income $(\$ A U)$} \\
\hline $100001+$ & $225 / 243$ & $92 \cdot 3$ & $1 \cdot 00$ & & \\
\hline $60001-100000$ & $241 / 253$ & $95 \cdot 0$ & 1.58 & $0 \cdot 79,3 \cdot 22$ & $0 \cdot 204$ \\
\hline $20001-60000$ & $289 / 321$ & $90 \cdot 0$ & 0.75 & $0 \cdot 40,1 \cdot 41$ & 0.374 \\
\hline Up to 20000 & $110 / 120$ & $91 \cdot 8$ & 0.93 & $0.43,2 \cdot 01$ & 0.857 \\
\hline Not stated/refused/don't know & $157 / 170$ & $92 \cdot 8$ & $1 \cdot 07$ & $0 \cdot 52,2 \cdot 22$ & 0.852 \\
\hline
\end{tabular}

*Not stated category not reported.

Table 8 Univariate analysis of related food variables and scaled trust variables associated with eating less than the recommended servings of fruit and vegetables per day among a random sample of the adult Australian population, 2009

\begin{tabular}{|c|c|c|c|c|c|}
\hline & $n / N$ & $\%$ & OR & $95 \%$ OR & $P$ value \\
\hline \multicolumn{6}{|l|}{ Consider food prices before health and nutrition* } \\
\hline Often/sometimes & $471 / 521$ & $90 \cdot 4$ & $1 \cdot 00$ & & \\
\hline Seldom/never & $537 / 572$ & 93.9 & $1 \cdot 63$ & $1 \cdot 04,2 \cdot 56$ & 0.035 \\
\hline \multicolumn{6}{|l|}{ How much of the food shopping do you do? } \\
\hline A lot & $634 / 704$ & $90 \cdot 0$ & $1 \cdot 00$ & & \\
\hline Some & $237 / 247$ & $95 \cdot 9$ & $2 \cdot 63$ & $1 \cdot 25,5 \cdot 52$ & 0.011 \\
\hline None/very little & $152 / 156$ & $97 \cdot 0$ & $3 \cdot 58$ & $1 \cdot 11,11 \cdot 49$ & 0.032 \\
\hline Overall level of importance with regard to the safety and quality of food & - & - & $0 \cdot 80$ & $0 \cdot 71,0 \cdot 90$ & $<0.001$ \\
\hline Overall importance of organisations monitoring safety and quality & - & - & $1 \cdot 04$ & $0 \cdot 99,1 \cdot 10$ & 0.132 \\
\hline Overall trust in groups & - & - & $1 \cdot 01$ & $0.98,1.03$ & 0.659 \\
\hline Overall trust in people/institutions & - & - & 0.93 & $0.84,1 \cdot 02$ & $0 \cdot 109$ \\
\hline Trust in groups following food scandal & - & - & $1 \cdot 03$ & $0 \cdot 88,1 \cdot 20$ & 0.743 \\
\hline
\end{tabular}

*Not stated category not reported.

were deemed unimportant. These aspects cover the fruit and vegetable supply chain from production to the handling and marketing of the products. It has previously been shown that 'food safety and quality are among the main consumer concerns, ${ }^{(44)}$, but for each of our models showing the lack of fruit and/or vegetable intake, safety and quality were unimportant and highlights an obvious target area. The inclusion of this variable in all three models could conceivably perhaps indicate a complacency or acceptance of the place of food production, possibly 
Table 9 Multivariate analysis of variables associated with respondents consuming less than the recommended servings of fruit and vegetables per day among a random sample of the adult Australian population, 2009

\begin{tabular}{|c|c|c|c|}
\hline & OR & $95 \%$ OR & $P$ value \\
\hline \multicolumn{4}{|l|}{ Sex } \\
\hline Female & $1 \cdot 00$ & & \\
\hline Male & $2 \cdot 23$ & $1 \cdot 30,3 \cdot 82$ & 0.004 \\
\hline \multicolumn{4}{|l|}{ Age (years) } \\
\hline $75+$ & $1 \cdot 00$ & & \\
\hline $55-74$ & $1 \cdot 08$ & $0.53,2.21$ & 0.828 \\
\hline $35-54$ & $1 \cdot 71$ & $0.81,3 \cdot 60$ & $0 \cdot 160$ \\
\hline $18-34$ & $3 \cdot 31$ & $1 \cdot 10,9 \cdot 98$ & 0.033 \\
\hline $\begin{array}{l}\text { Overall level of importance } \\
\text { with regard to the safety } \\
\text { and quality of food }\end{array}$ & $0 \cdot 87$ & $0.78,0.98$ & 0.024 \\
\hline
\end{tabular}

*Not stated category not reported.

highlighting a lack of interest in food overall or a lack of reflexivity or control. While one of the variables that may have measured an interest in food (how much food shopping undertaken by the responders) was significant only in the vegetable model, the other variable (consideration of food prices before health and nutritional aspects) was not significant in either of the multivariate models. Alternatively, this seeming lack of interest in food could be, as argued by Lupton, the result of the geographical diversity of Australia that allows a wide range of food production and a focus on exporting food rather than importing perhaps suspect, fresh food products ${ }^{(45)}$. Also important in the psyche of Australians is the lack of any major food scare such as those seen in other regions/ countries specifically Europe, the UK and China ${ }^{(46)}$. The absence of major food crises in Australia perhaps encourages a lack of importance of safety and quality concerns especially for this group that do not heed current nutritional recommendations.

Included in the final model for people eating less than the recommended servings of vegetables were two somewhat contradictory variables. First, an increase in trust in groups (such as family, neighbours, hospitals, governments, banks) was found. Second, a decrease in trust in people/organisations such as press, radio and television, supermarket chains, farmers and politicians in general was found. If these latter organisations could be deemed 'scientific experts' other studies have also reported an overall high level of distrust in scientific experts, government sources and the food industry, although research has also shown that this level of distrust of the 'scientific experts' is more common among men ${ }^{(12,17)}$. The lack of trust in government has also been reported ${ }^{(17)}$. Previous findings have also reported women and those with higher education levels have more trust in scientific experts ${ }^{(12)}$. While neither of these continuous variables was related to trust of food per se, it is interesting that those who do not eat enough vegetables have a significantly higher level of trust of the broad community spectrum of society (from family to the medical system to broad levels of government) indicating, perhaps, a willingness to accept these bodies as authoritarian. This finding may also be explained by the fact that respondents may not have been familiar with all of the listed organisations and therefore unsure of whether they trusted them.

Increasing fruit and vegetable consumption relies on many things including a liking of fruit and vegetables ${ }^{(47)}$, cost, supply, access and availability ${ }^{(48)}$, taste ${ }^{(32)}$, current recommendations ${ }^{(47,49)}$, and willingness to change and time pressures ${ }^{(50)}$. Although many campaigns focus on both fruit and vegetables as one ${ }^{(1,51)}$, the present analysis has shown that fruit and vegetables have different factors involved in predicting their consumption. Of the five scores, only one - importance of safety and quality - was reproduced in the alternative multivariate models, although similarities did exist at the univariate level. This again highlights the need for different target messages aimed at increasing fruit and vegetables separately.

We acknowledge several weaknesses in the present cross-sectional study. The self-report nature of the data collection could result in socially desirable responses or problems with recall. The response rate of nearly $41 \%$ is acceptable for this type of survey but the potential for survey non-response bias is acknowledged. Response rates are declining in surveys based on all forms of interviewing $^{(52,53)}$ as people have become more active in protecting their privacy. The growth of telemarketing has disillusioned the community and diminished the success of legitimate social science research by means of telephone-based surveys. Other weaknesses of the study are the lack of validation of the derived scores and the fact that these data elements were collected with a range of other variables that were not included in the analysis. This exclusion of these other variables did not allow for consideration of potential confounders. In addition, the use of dichotomised fruit and vegetable variables based on the recommended intake could be seen as a weakness of the analysis. State and national targets in Australia for increasing fruit and vegetable intake, together with major social marketing campaigns, are based on increasing the actual number of servings rather than the mean number of servings and hence the reason for our dichotomisation of the variables. Notwithstanding these weaknesses, the strength of the study includes the random nature of the sample and the large number and variety of the associated variables.

The present study attempted to incorporate a range of trust-related variables and demographic and socioeconomic indicators to help profile those who eat less than the recommended daily servings of fruit and vegetables. In the endeavour to change behaviours, especially in regard to increasing fruit and vegetable consumption, research into a broad range of determinants associated with the behaviours should be coupled with a deeper 
understanding of the process associated with changing the behaviours ${ }^{(54)}$. Understanding the complexity of these relationships is challenging but the present research has attempted to highlight some unique findings that may assist in this endeavour. As argued by Willett ${ }^{(14)}$, eating in our Western modern society is an act of trust - trust that those producing the food either directly via farmers or via production methods are 'providing us with healthy foodstuffs'. While trust is on the causal pathway for behaviour change ${ }^{(12)}$, knowledge and attitudes about aspects associated with safety and quality of food are, as highlighted by our research, also of importance.

\section{Acknowledgements}

This work was supported by an Australian Research Council Discovery grant. The authors have no conflict of interest. A.W.T. participated in the design and co-ordination of the study, gained the funding and drafted the manuscript. J.C. and P.R.W. conceived the design of the study, gained the funding, participated in the co-ordination of the study and were involved in the drafting of the manuscript. J.H. and S.B.M. participated in the design and co-ordination of the study and were involved in the drafting of the manuscript. R.P. participated in the co-ordination of the study, undertook statistical analyses and was involved in the drafting of the manuscript. T.K.G. undertook statistical analyses and was involved in the drafting of the manuscript. The authors acknowledge the dedication and professionalism of the interviewers of Harrison Health Research.

\section{References}

1. Pollard CM, Lewis JM \& Binns CW (2008) Selecting interventions to promote fruit and vegetable consumption: from policy to action, a planning framework case study in Western Australia. Aust N Z Health Policy 5, 27.

2. World Health Organization (2003) Diet, Nutrition and the Prevention of Chronic Diseases. WHO Technical Report Series no. 916. Geneva: WHO.

3. Alinia S, Hels O, Tetens I et al. (2009) The potential association between fruit intake and body weight - a review. Obes Rev 10, 639-647.

4. The National Obesity Taskforce (2003) Healthy Weight 2008 - Australia's Future. Canberra: Department of Health \& Ageing; available at http://www.healthyactive.gov.au/ publications.htm

5. Giskes K, Van Lenthe FJ, Kamphuis CBM et al. (2009) Household and food shopping environments: do they play a role in socioeconomic inequalities in fruit and vegetable consumption? A multilevel study among Dutch adults. J Epidemiol Community Health 63, 113-120.

6. Siegrist M, Stampfli N \& Kastenholz H (2008) Consumer's willingness to buy functional foods: the influence of carrier, benefit and trust. Appetite 51, 526-529.

7. Coveney J (2007) Food and trust in Australia: building a picture. Public Health Nutr 11, 237-245.

8. Wiedemann AU, Lippke S, Reuter T et al. (2009) Predictions of stage transitions in fruit and vegetable intake. Health Educ Res 24, 596-607.
9. Baranowski T, Cullen KW, Nicklas T et al. (2003) Are current health behavioral change models helpful in guiding prevention of weight gain efforts? Obes Res 11, Suppl. 2, 23S-43S.

10. Earle TC \& Siegrist M (2008) On the relationship between trust and fairness in environmental risk management. Risk Anal 28, 1395-1413.

11. Dibben MR \& Lean MEJ (2003) Achieving compliance in chronic illness management: illustrations of trust relationships between physicians and nutrition clinic patients. Health Risk Soc 5, 241-258.

12. Bleich S, Blendon R \& Adams A (2007) Trust in scientific experts on obesity: implications for awareness and behavior change. Obesity (Silber Spring) 15, 2145-2156.

13. Siegrist M, Cousin ME, Kastenholz H et al. (2007) Public acceptance of nanotechnology foods and food packaging: the influence of affect and trust. Appetite $\mathbf{4 9}$, 459-466.

14. Willett WC (2007) Confusion at the table: can we trust that our food is healthy? In The Trust Crisis in Healthcare: Causes, Consequences, and Cures, pp. 122-130 [DA Shore, editor]. New York: Oxford University Press.

15. Coombes R (2005) Public distrusts government health campaigns, experts says. BMJ 331, 70.

16. McComas KA (2008) Nutrition communication. The role of trust in health communication and the effects of conflicts of interest among scientists. Proc Nutr Soc 67, 428-436.

17. Frewer LJ \& Miles S (2003) Temporal stability of the psychological determinants of trust: implications for communication about food risks. Health Risk Soc 5, 259-271.

18. Hansen J, Holm L, Frewer L et al. (2003) Beyond the knowledge deficit: recent research into lay and expert attitudes to food risks. Appetite 41, 111-121.

19. Kjaernes U, Harvey M \& Ward A (2007) Trust in Food: A Comparative and Institutional Analysis. Basingstoke: Palgrave.

20. Vilella-Vila M \& Costa-Font J (2008) Press media reporting effects on risk perceptions and attitudes towards genetically modified (GM) food. J SocioEcon 37, 2095-2106.

21. Coulson N (2002) Source of food safety information: whom do adolescents trust? Appetite 38, 199-200.

22. Kreuter MW \& Wray RJ (2003) Tailored and targeted health communications: strategies for enhancing information relevance. Am J Health Behav 27, Suppl. 3, S227-S232.

23. Eyles HC \& Mhurchu CN (2009) Does tailoring make a difference? A systematic review of the long-term effectiveness of tailored education for adults. Nutr Rev 67, 464-480.

24. Henderson J, Coveney J, Ward P et al. (2009) Governing childhood obesity: framing regulation of fast food advertising in the Australian print media. Soc Sci Med 69, $1402-1408$.

25. Henderson J, Ward PR, Coveney J et al. (2010) What are the important issues around food safety and diet? Findings from a media analysis and a qualitative study of consumer trust. Aust Med J 3, 164-169.

26. Henderson J, Coveney J \& Ward P (2010) Who regulates food? Australians' perceptions of responsibility for food safety. Aust J Prim Health 16, 344-351.

27. Holmberg L, Coveney J, Henderson J et al. (2010) What should primary health care practitioners know about factors influencing young people's food choice? Aust Med J3, 156-163.

28. Hosmer DW \& Lemeshow S (1989) Applied Logistic Regression. New York: John Wiley and Sons.

29. Pollard CM, Daly AM \& Binns CW (2008) Consumer perceptions of fruit and vegetable serving sizes. Public Health Nutr 12, 637-643.

30. State Government of Victoria (2008) Victorian Population Health Survey 2007. Melbourne: Department of Human Services, Victoria. 
31. Population Research \& Outcome Studies Unit (2010) The Health Status of People Living in the South Australian Health Regions - January 2004 to December 2009. Adelaide: South Australian Department of Health.

32. Schatzer M, Rust P \& Elmadfa I (2010) Fruit and vegetables intake in Australian adults: intake frequency serving sizes, reasons for and barriers to consumption, and potential for increasing consumption. Public Health Nutr 13, 480-487.

33. Australian Institute of Health and Welfare (2010) Prevalence of risk factors for chronic diseases. http://www.aihw. gov.au/cdarf/data_pages/prevalnce_risk_factors/index.cfm (accessed October 2010).

34. Centers for Disease Control and Prevention (2007) Prevalence of fruit and vegetable consumption and physical activity by race/ethnicity - United States, 2005. MMWR Morb Mortal Wkly Rep 56, 301-304.

35. Magarey A, McKean S \& Daniles L (2006) Evaluation of fruit and vegetable intakes of Australian adults: the National Nutrition Survey 1995. Aust N Z J Public Health 30, 32-37.

36. Satheannoppakao W, Aekplakorn W \& Pradipasen M (2009) Fruit and vegetables consumption and its recommended intake associated with sociodemographic factors: Thailand National Health Examination Survey III. Public Health Nutr 12, 2192-2198.

37. Bihan H, Casterbon K, Mejean C et al. (2010) Socioeconomic factors and attitudes towards food affordability and health are associated with fruit and vegetable consumption in a low-income population. J Nutr 140, 823-830.

38. Lallukka T, Pitaniemi J, Rahkonen O et al. (2010) The association of income with fresh fruit and vegetable consumption at different levels of education. Eur J Clin Nutr 64, 324-327.

39. Riediger ND \& Moghadasian MH (2008) Patterns of fruit and vegetable consumption and the influence of sex, age and socio-demographic factors among Canadian elderly. J Am Coll Nutr 27, 306-313.

40. Giskes K, Turrell G, Patterson C et al. (2002) Socioeconomic differences in fruit and vegetable consumption among Australian adolescents and adults. Public Health Nutr 5, 663-669.

41. Dumbrell S \& Mathai D (2008) Getting young men to eat more fruit and vegetables: a qualitative investigation. Health Promot J Aust 19, 216-221.
42. Appleton KM, McGill R \& Woodside JV (2009) Fruit and vegetable consumption in older individuals in Northern Ireland: levels and patterns. Br J Nutr 102, 949-953.

43. Nooyens ACJ, Visscher TLS, Schuit AJ et al. (2005) Effects of retirement on lifestyle in relation to changes in weight and waist circumference in Dutch men: a prospective study. Public Health Nutr 8, 1266-1274.

44. Kuhar A \& Juvancic L (2010) What determines purchasing behaviour for organic and integrated fruits and vegetables? Bulg J Agric Sci 16, 111-122.

45. Lupton DA (2005) Lay discourses and beliefs related to food risks: an Australian perspective. Sociol Health Illn 27, 448-467.

46. Van Wezemael L, Verbeke W, Kugler JO et al. (2010) European consumers and beef safety: perceptions, expectations and uncertainty reduction strategies. Food Control 21, 835-844.

47. Appleton KM, McGill R, Neville C et al. (2009) Barriers to increasing fruit and vegetable intakes in the older population of Northern Ireland: low levels of liking and low awareness of current recommendations. Public Health Nutr 13, 514-521.

48. Caldwell EM, Kobayashi MM, DuBow WM et al. (2009) Perceived access to fruits and vegetables associated with increased consumption. Public Health Nutr 12, 1743-1750.

49. Kristjansdottir AG, Bourdeaudhuij I, Klepp KI et al. (2009) Children's and parents' perception of the determinants of children's fruit and vegetable intake in a low-intake population. Public Health Nutr 12, 1224-1233.

50. Welch N, McNaughton SA, Hunter W et al. (2009) Is the perception of time pressure a barrier to healthy eating and physical activity among women? Public Health Nutr 12, 888-895.

51. Catford J (2000) Eat Well Australia: developing a national strategic framework for public health nutrition. Asia Pac J Clin Nutr 9, Suppl. S1, S65-S71.

52. Groves RM (2006) Nonresponse rates and nonresponse bias in household surveys. Public Opin Q 70, 646-675.

53. Curtin R, Presser S \& Singer E (2005) Changes in telephone survey nonresponse over the past quarter century. Public Opin Q 69, 87-88.

54. Noar SM \& Zimmerman RS (2005) Health behaviour theory and cumulative knowledge regarding health behaviors: are we moving in the right direction? Health Educ Res 20, 275-290. 